\title{
Socioeconomic Correlates and Key Aspects of Tobacco Surveillance Using Global Adult Tobacco Survey Among College Students of Mangaluru, South India
}

\author{
Praveen S. Jodalli ${ }^{1}$, Ganesh Shenoy Panchmal ${ }^{2}$ \\ 1. Public Health Dentistry, Yenepoya Dental College and Hospital, Mangalore, IND 2. Public Health \\ Dentistry, Yenepoya Dental College and Hospital, Mangaluru, IND
}

$\square$ Corresponding author: Praveen S. Jodalli, praveenjodalli@gmail.com

\section{Abstract}

\section{Introduction}

Tobacco use in recent times has been identified to be the single biggest cause of morbidity and mortality. The epidemic of tobacco use has increased among young adults, which has changed the equation of the prevalence. The contribution of tobacco use to socioeconomic inequalities in health is increasing in India. Adolescent's tobacco use may play an important role in increasing social inequalities related to smoking and smokeless tobacco use. The objective of this research was to study the association between socioeconomic status and tobacco use among college students of Mangaluru, South India

\section{Methods}

To analyze the association between the socioeconomic status and tobacco use, the study was conducted among 18 to 24-year-old college students $(n=802)$ in different colleges of Mangaluru, South India. A subset of key questions from the Global Adult Tobacco Survey (GATS) was used. The socioeconomic status of the participants was recorded using Kuppuswamy socioeconomic scale (for India) to categorize them into upper class and lower class. Descriptive statistics were applied to assess the factors related to tobacco use and socioeconomic status using SPSS ver. 24.0.

\section{Results}

Approximately $29.7 \%$ males and $70.3 \%$ of females completed the interview. Among 802 subjects, $69.9 \%$ belonged to the upper class and $30.04 \%$ belonged to the lower class. The current smokers who smoked daily $1.7 \%$ were from the upper class and $1.7 \%$ were from the lower class; no statistically significant difference was observed as well $(p=0.97)$. Approximately $3.4 \%$ from the upper class smoked less than daily and 3.1\% from lower class smoked less than daily (NS). Among the upper class, $1.8 \%$ used daily and $2 \%$ subjects from the lower class used smokeless tobacco. A statistically significant difference was observed with subjects between the upper and lower class in noticing cigarette promotions in various forms during the last 30 days of interview.

\section{Conclusion}

Socioeconomic disparities on tobacco use need to be explored to ensure the initiation of new tobacco control activities and monitor the existing tobacco control policies. The current study finding demonstrates a significant but varied role of socioeconomic status on current and past 
Categories: Epidemiology/Public Health

Keywords: tobacco use, smoking, smokeless tobacco, socioeconomic status

\section{Introduction}

Tobacco use causes more than five million deaths annually and it is the leading preventable cause of death in the world [1-2]. By 2030, it is estimated that about $80 \%$ of deaths related to tobacco use will occur in middle-income and low-income counties [2]. A strong momentum at the global level against tobacco use is established by the Framework Convention on Tobacco Control through the World Health Organization (WHO) [3-5]. Overall, there is an increase in attention to the pattern of tobacco use in the low- and middle-income countries.

India is the third largest tobacco-producing nation and the second largest consumer of tobacco products. The Global Adult Tobacco Survey-2 (GATS-2) for India revealed that the prevalence of current tobacco use in any form among adults is $28.6 \%$ (266.8 million individuals) among adults aged 15 and above. From GATS-1 in 2009-2010 to GATS-2 in 2016-2017, the prevalence of any form of tobacco use has decreased significantly by $6 \%$ from $34.6 \%$ to $28.6 \%$. The relative decrease in the prevalence of tobacco use is $17.3 \%$ [6].

The tobacco epidemic varies significantly from country to country. A systematic review and meta-analysis published in 2017 found a consistent inverse dose-response relationship between cigarette smoking and income level in the WHO regions for the United States of America, South East Asia, Europe, and Western Pacific [7]. In the low- and middle-income countries, it was found that the socioeconomic inequalities do exist in the pattern of tobacco use [8]. The pattern of tobacco use is inversely related to the socioeconomic status, with disadvantaged groups in the population being more likely to take up and continue smoking [9]. The exact mechanism behind the socioeconomic differences in smoking/smokeless tobacco use is unknown, but they have been linked to impoverished environments and lack of access to positive activities and alternatives to drugs [10].

Along with socioeconomic status of the families, young adult behaviors are influenced by their educational institutions. The socioeconomic environment where the school/college is located may influence the tobacco use pattern through several mechanisms, including exposure to tobacco advertisement, availability of tobacco products, and the development of social norms that facilitate youth smoking [11-13]. However, we could not find literature in regard to this in the developing countries like India that would address the impact of socioeconomic context of the colleges among students. The primary objective of the study was to find the relationship between socioeconomic status and the tobacco use among the students in the colleges of Mangaluru, south India.

\section{Materials And Methods}

This study was implemented to explore tobacco use among the population aged 18-24 years, men and women, attending colleges in Mangaluru. The tobacco use status and sociodemographic data were determined based on the questions from the GATS. A total of 802 subjects completed the interview. The GATS subset questionnaire consists of a core set of questions, which gathered information on the subject's background characteristics, tobacco use (smoked or smokeless). The socioeconomic status of the participants was recorded using Kuppuswamy socioeconomic scale (for India); further, the study participants were categorized as upper class and lower class. The sample for the study was selected from the colleges using a multistage design to ensure that adequate coverage of the entire target population while 
simultaneously minimizing the data collection costs. The target population for this study included both men and women aged 18-24 years old who considered Mangaluru to be their primary place of residence, who consented to be part of the study. Our study excluded the institutionalized population and the subjects unwilling to consent.

\section{Study variables}

Information on tobacco use that included smoking and smokeless tobacco was recorded keeping a focus on daily smoking/chewing, less than daily smoking/chewing or not at all. Other variables assessed were exposure of the study subjects in the past 30 days to second-hand smoke (at home/outdoor), quit attempts, anti-tobacco warnings on cigarette advertisements. Relevant independent variables included in the analysis were gender (male/female), age, place of residence, socioeconomic status where the education of head of the family, income per month, and occupation are considered, and the subject is categorized to be belonging to the upper class and lower class.

\section{Statistical analysis}

Data were entered in Microsoft Excel worksheet and analyzed using SPSS ver. 24.0. Descriptive statistics are presented in the form of frequency percentage. Chi-square test was used to study the association between the study variables.

\section{Results}

Table 1 shows the distribution of study subjects by age, gender, and socioeconomic status. It was observed that there was a statistically significant difference observed between males and females. Approximately $2.4 \%$ of females smoked tobacco less than daily basis compared to $5.4 \%$ of males $(p<0.01)$. 


\section{Cureus}

\begin{tabular}{|c|c|c|c|c|c|c|}
\hline & & \multicolumn{2}{|c|}{ Socioeconomic status } & \multirow{2}{*}{ Total } & \multicolumn{2}{|l|}{ Chi-square test } \\
\hline & & Upper class & Lower class & & Chi-square value & $p$-value \\
\hline \multirow{3}{*}{ Gender } & & 168 & 70 & 238 & \multirow{7}{*}{0.07} & \multirow{3}{*}{0.80 (NS) } \\
\hline & & $29.9 \%$ & $29.0 \%$ & $29.7 \%$ & & \\
\hline & Females & $70.1 \%$ & $71.0 \%$ & $70.3 \%$ & & \\
\hline \multirow{5}{*}{ Age } & & 501 & 207 & 708 & & \multirow{4}{*}{$0.54(\mathrm{NS})^{\#}$} \\
\hline & & $89.3 \%$ & $85.9 \%$ & $88.3 \%$ & & \\
\hline & \multirow{3}{*}{$>20-24$} & 60 & 34 & 94 & & \\
\hline & & & & & & \\
\hline & & $10.1 \%$ & $14 \%$ & $11.1 \%$ & & \\
\hline
\end{tabular}

TABLE 1: Distribution of study participants by age, gender, and socioeconomic status

\#Fisher's exact test

${ }^{*} P<0.05$, statistically significant; $P>0.05$, non-significant, NS

The association between tobacco use and gender is shown in Table 2 . A statistically significant difference was observed with the smoking status between genders; $4.9 \%$ of the males smoked on a daily basis and $0.4 \%$ females smoked tobacco on daily basis $(p<0.05)$. Our study findings showed $5.4 \%$ of males and $2.4 \%$ occasional smokers who smoked less than daily. Approximately $58.5 \%$ of females among the current smokers were smoking on a daily basis in the past as compared to $45.5 \%$ males $(p=0.54)$. The current smokeless tobacco users in the study had $3 \%$ males and $1.5 \%$ females. Occasionally, tobacco was chewed on a less than daily basis by $2.6 \%$ males and $2.6 \%$ females $(p=0.36)$. It was also seen that there were no females in the study who chewed smokeless tobacco in the past or on a daily basis, whereas $40 \%$ of males chewed tobacco in the past and $1.8 \%$ chewed it on a daily basis.

\begin{tabular}{|c|c|c|c|c|c|c|}
\hline & & \multicolumn{2}{|c|}{ Gender } & \multirow{2}{*}{ Total } & \multicolumn{2}{|l|}{ Chi-square test } \\
\hline & & Males & Females & & Chi-square value & p-value \\
\hline \multirow{6}{*}{ Current tobacco smoking status } & \multirow{2}{*}{ Daily } & 11 & 2 & 13 & \multirow{6}{*}{24.17} & \multirow{6}{*}{$<0.001^{*}$} \\
\hline & & $4.9 \%$ & $0.4 \%$ & $1.7 \%$ & & \\
\hline & \multirow{2}{*}{ Less than daily } & 12 & 13 & 25 & & \\
\hline & & $5.4 \%$ & $2.4 \%$ & $3.3 \%$ & & \\
\hline & \multirow{2}{*}{ Not at all } & 200 & 520 & 720 & & \\
\hline & & $89.7 \%$ & $97.2 \%$ & $95.0 \%$ & & \\
\hline
\end{tabular}




\section{Cureus}

Yes

Past daily smoking status

$\begin{array}{llll}5 & 7 & 12\end{array}$

$5.5 \% \quad 58.3 \% \quad 52.2 \%$

$5 \quad 11$

0.38

$0.54(\mathrm{NS})$

No

$54.5 \% \quad 41.7 \% \quad 47.8 \%$

$5 \quad 2 \quad 7$

Daily

$2.5 \% \quad 0.4 \% \quad 1.0 \%$

Past smoking status

Less than daily

$\begin{array}{lll}7 & 6 & 13\end{array}$

\section{Past smoking status}

Current smokeless tobacco use

Less than daily

$3.5 \%$

$1.2 \%$

$1.8 \%$

$186 \quad 504 \quad 690$

Not at all

$93.9 \% \quad 98.4 \% \quad 97.2 \%$

Daily

$\begin{array}{lll}7 & 8 & 15\end{array}$

Not at all

$3.0 \%$

$1.5 \%$

$1.9 \%$

$6 \quad 14 \quad 20$

$2.6 \% \quad 2.6 \% \quad 2.6 \%$

$221 \quad 526 \quad 747$

$94.4 \% \quad 96.0 \% \quad 95.5 \%$

$2 \quad 0 \quad 2$

Yes

$40.0 \% \quad 0.0 \% \quad 10.5 \%$

Past daily smokeless tobacco use

$3 \quad 14 \quad 17$

No

$$
60.0 \% \quad 100.0 \% \quad 89.5 \%
$$

$4 \quad 0 \quad 4$

Daily

$1.8 \% \quad 0.0 \% \quad 0.5 \%$

$\begin{array}{lllll} & 5 & 9 & 14 & \\ \text { Less than daily } & & & & \\ & 2.3 \% & 1.8 \% & 1.9 \% & \\ & & & & \\ \text { Not at all } & 210 & 500 & 710 & \\ & 95.9 \% & 98.2 \% & 97.5 \%\end{array}$

Past smokeless tobacco use

\section{TABLE 2: Measuring tobacco use prevalence (smoked/smokeless) in association with} gender

\footnotetext{
\#Fisher's exact test

${ }^{*} p<0.05$, statistically significant; $P>0.05$, non-significant, NS
} 


\section{Cureus}

Table 3 shows the association between socioeconomic status and current, past daily smoking status and past smoking status. 1.7\% of the subjects from the upper and lower class were smoking on a daily basis whereas 3.4\% from the upper class, 3.1\% from the lower class smoked tobacco on a less than daily basis. No statistically significant difference was observed between the subjects from the upper and lower class $(p=0.97)$. The current non-smokers, subjects from upper class $1.2 \%$ smoked daily, $1 \%$ less than daily and lower class $0.5 \%$ smoked daily and $3.7 \%$ less than daily. The upper class is more likely to have smoked daily, less than daily as compared to the lower socioeconomic class $(p=0.04)$. It was observed that the prevalence of smokeless tobacco use on a daily basis was $1.8 \%$ among upper status and $2.1 \%$ of lower status and $2.4 \%$ in upper status and $3 \%$ in lower status on a less than daily basis which was not statistically significant $(p=0.84)$. Among less than daily smokeless tobacco users, $28.6 \%$ from lower status have used smokeless tobacco in the past, whereas none from the upper socioeconomic status have been used in the past.

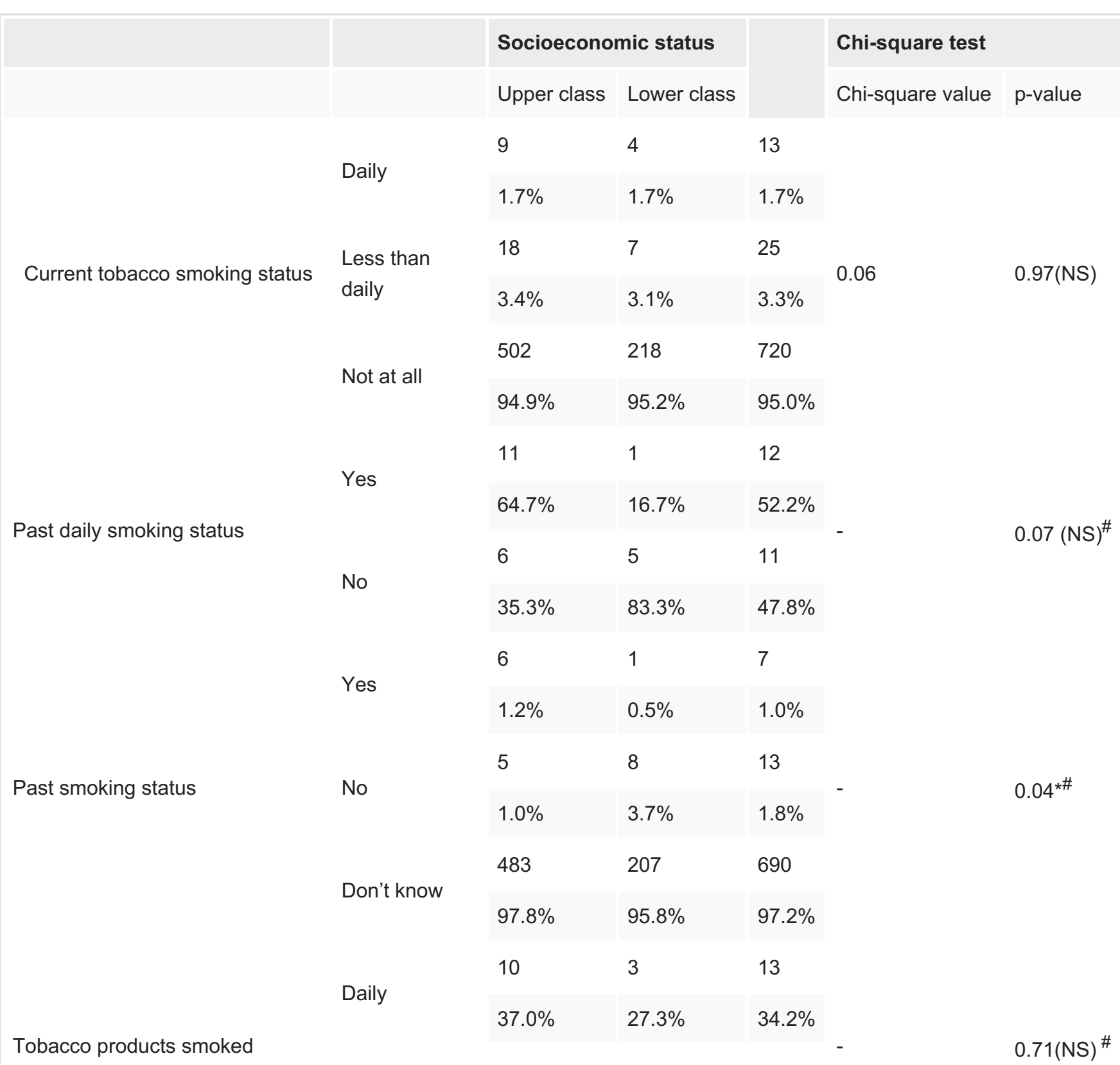




\section{Cureus}

\begin{tabular}{|c|c|c|c|c|c|c|}
\hline & & 17 & 8 & 25 & & \\
\hline & & $63.0 \%$ & $72.7 \%$ & $65.8 \%$ & & \\
\hline & & 10 & 5 & 15 & & \\
\hline & Dally & $1.8 \%$ & $2.1 \%$ & $1.9 \%$ & & \\
\hline & Less than & 13 & 7 & 20 & & \\
\hline & daily & $2.4 \%$ & $3.0 \%$ & $2.6 \%$ & 0.04 & $0.04(\mathrm{INS})$ \\
\hline & & 525 & 222 & 747 & & \\
\hline & IVUl di dil & $95.8 \%$ & $94.9 \%$ & $95.5 \%$ & & \\
\hline & & 0 & 2 & 2 & & \\
\hline & ros & $0.0 \%$ & $28.6 \%$ & $10.5 \%$ & & \\
\hline Past daily smokeless tobacco use & & 12 & 5 & 17 & - & $0.12(\mathrm{NS})^{\#}$ \\
\hline & No & $100.0 \%$ & $71.4 \%$ & $89.5 \%$ & & \\
\hline & & 4 & 0 & 4 & & \\
\hline & Daliy & $0.8 \%$ & $0.0 \%$ & $0.5 \%$ & & \\
\hline & Less than & 11 & 3 & 14 & & \\
\hline Past smokeless tobacco use & daily & $2.2 \%$ & $1.4 \%$ & $1.9 \%$ & & $0.42(\mathrm{NS})^{\#}$ \\
\hline & & 495 & 215 & 710 & & \\
\hline & & $97.1 \%$ & $98.6 \%$ & $97.5 \%$ & & \\
\hline
\end{tabular}

\section{TABLE 3: Measuring tobacco use prevalence (smoked/smokeless) in association with socioeconomic status}

${ }^{\#}$ Fisher's exact test

${ }^{*} p<0.05$ statistically significant; $p>0.05$, non-significant, NS

A summary description of the tobacco questions and the corresponding analysis indicators in association with the socioeconomic status of the subjects is shown in Table 4. No significant difference between the classes was observed when it came to frequency of subjects smoking inside their homes, on a daily, less than daily, monthly or less than a monthly basis $(p=0.91)$. It was observed that, among the subjects from the upper class, $48.1 \%$ attempted to quit smoking habit in the last 12 months when compared to subjects from lower status but the results were not statistically significant $(p=0.72)$. A statistically significant difference was observed between the classes when the overall sample was observed for noticing in the past 30 days (free sample of cigarettes, cigarettes at sale prices, coupons for cigarettes, free gifts or discounts on other products when buying cigarettes, clothing or other items with a cigarette brand name or 


\section{Cureus}

logo, cigarette promotions in the mail $(p<0.05)$.

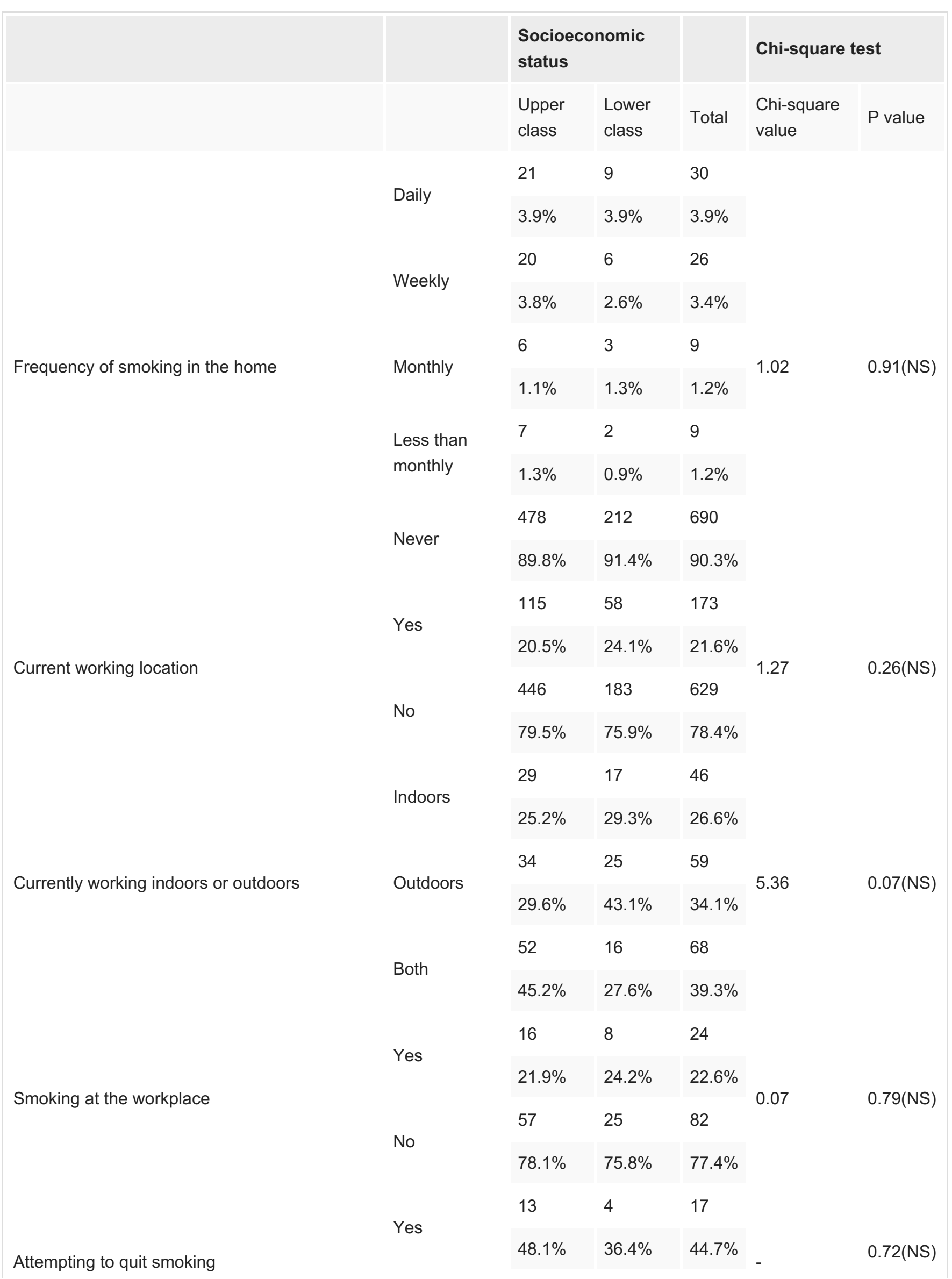




\section{Cureus}

Visiting a doctor

Receiving cessation advice from doctors

Anti-cigarette information in newspapers/magazines

Noticing health warning on cigarette packs

Noticing anti-cigarette information on television

Thinking about quitting because of warning on cigarette packs

Cigarette advertising in store
No

Yes

No

Yes

No

Yes

No

Yes

No

$\begin{array}{lll}51.9 \% & 63.6 \% & 55.3 \% \\ 14 & 5 & 19 \\ 51.9 \% & 45.5 \% & 50.0 \%\end{array}$

$13 \quad 6 \quad 19$

0.13

0.72 (NS)

$48.1 \% \quad 54.5 \% \quad 50.0 \%$

$4 \quad 1 \quad 5$

$28.6 \% \quad 20.0 \% \quad 26.3 \%$

$1.00(\mathrm{NS})$

$\begin{array}{lll}10 & 4\end{array}$

\#

$71.4 \% \quad 80.0 \% \quad 73.7 \%$

$338 \quad 135 \quad 473$

$68.8 \% \quad 65.5 \% \quad 67.9 \%$

$153 \quad 71 \quad 224$

0.73

0.39 (NS)

$31.2 \% \quad 34.5 \% \quad 32.1 \%$

$370 \quad 156 \quad 526$

$73.1 \% \quad 71.9 \% \quad 72.8 \%$

$136 \quad 61 \quad 197$

$26.9 \% \quad 28.1 \% \quad 27.2 \%$

$334 \quad 146 \quad 480$

Yes

$59.5 \% \quad 60.6 \% \quad 59.9 \%$

$150 \quad 61 \quad 211$

No

$0.73(\mathrm{NS})$

$26.7 \% \quad 25.3 \%$

$\begin{array}{lll}77 & 34 & 111\end{array}$

Did not see

$13.7 \% \quad 14.1 \% \quad 13.8 \%$

$156 \quad 60 \quad 216$

Yes

$\begin{array}{lcccc}37.6 \% & 36.1 \% & 37.2 \% & & \\ 259 & 106 & 365 & & 0.11\end{array}$

No

$62.4 \% \quad 63.9 \% \quad 62.8 \%$

$153 \quad 70 \quad 223$

$31.6 \% \quad 35.2 \% \quad 32.7 \%$

$331 \quad 129 \quad 460$

\%




\section{Cureus}

$68.4 \% \quad 64.8 \% \quad 67.3 \%$

Noticing Cigarette promotions

\begin{tabular}{|c|c|c|c|c|c|c|}
\hline \multirow{4}{*}{ Free sample samples of cigarettes? } & & 7 & 11 & 18 & \multirow{4}{*}{8.97} & \multirow{4}{*}{$0.003^{*}$} \\
\hline & & $1.4 \%$ & $5.2 \%$ & $2.5 \%$ & & \\
\hline & \multirow{2}{*}{ No } & 498 & 199 & 697 & & \\
\hline & & $98.6 \%$ & $94.8 \%$ & $97.5 \%$ & & \\
\hline \multirow{4}{*}{ Cigarettes at sale prices? } & & 16 & 10 & 26 & \multirow{4}{*}{0.96} & \multirow{4}{*}{$0.33(\mathrm{NS})$} \\
\hline & & $3.2 \%$ & $4.7 \%$ & $3.6 \%$ & & \\
\hline & \multirow{2}{*}{ No } & 485 & 203 & 688 & & \\
\hline & & $96.8 \%$ & $95.3 \%$ & $96.4 \%$ & & \\
\hline \multirow{4}{*}{ Coupons for cigarettes? } & \multirow{2}{*}{ Yes } & 2 & 5 & 7 & \multirow{4}{*}{ - } & \multirow{4}{*}{$0.03^{\star \#}$} \\
\hline & & $0.4 \%$ & $2.4 \%$ & $1.0 \%$ & & \\
\hline & \multirow{2}{*}{ No } & 502 & 207 & 709 & & \\
\hline & & $99.6 \%$ & $97.6 \%$ & $99.0 \%$ & & \\
\hline \multirow{4}{*}{ Free gifts /discounts on cigarettes? } & \multirow{2}{*}{ Yes } & 2 & 5 & 7 & \multirow{4}{*}{ - } & \multirow{4}{*}{$0.03^{\star \#}$} \\
\hline & & $0.4 \%$ & $2.4 \%$ & $1.0 \%$ & & \\
\hline & \multirow{2}{*}{ No } & 498 & 206 & 704 & & \\
\hline & & $99.6 \%$ & $97.6 \%$ & $99.0 \%$ & & \\
\hline \multirow{4}{*}{$\begin{array}{l}\text { Clothing or items with cigarette brand name or } \\
\text { logo? }\end{array}$} & \multirow{2}{*}{ Yes } & 6 & 4 & 10 & \multirow{4}{*}{-} & \multirow{4}{*}{$\begin{array}{l}0.49 \text { (NS) } \\
\#\end{array}$} \\
\hline & & $1.2 \%$ & $1.9 \%$ & $1.4 \%$ & & \\
\hline & \multirow{2}{*}{ No } & 493 & 207 & 700 & & \\
\hline & & $98.8 \%$ & $98.1 \%$ & $98.6 \%$ & & \\
\hline \multirow{4}{*}{ Cigarette promotion in the mail? } & \multirow{2}{*}{ Yes } & 3 & 6 & 9 & \multirow{4}{*}{ - } & \multirow{4}{*}{$0.02^{\star \#}$} \\
\hline & & $0.6 \%$ & $2.8 \%$ & $1.3 \%$ & & \\
\hline & \multirow{2}{*}{ No } & 496 & 206 & 702 & & \\
\hline & & $99.4 \%$ & $97.2 \%$ & $98.7 \%$ & & \\
\hline
\end{tabular}

TABLE 4: Tobacco use questions and the corresponding analysis indicators in association with the socio-economic status of the subjects

${ }^{\#}$ Fisher's exact test

${ }^{*} p<0.05$, statistically significant; $p>0.05$ non-significant, NS 


\section{Discussion}

The present study reports information about tobacco use among students belonging to the upper and lower socioeconomic strata. Smoking has a bigger magnitude among men than smokeless tobacco. However, both are consistent as the prevalence is considerably more among the males belonging to the upper socioeconomic status. The result of the use of smoked tobacco being more can be attributed to the addictive nature of tobacco consistent with other findings [14]. Low prevalence of tobacco use among the study population was observed. This could be suggestive of the present ban on advertising, and Cigarettes and other Tobacco Products Act (COTPA) in India have been effective tools in curbing the tobacco menace.

The present study showed that there was no statistically significant difference between males and females and subjects belonging to the upper and lower class regarding smoked and smokeless tobacco use. Interestingly, in this study, it was observed that females smoked less than daily more frequently than males. However, this pattern cannot be taken for granted or ignored. Research states that, worldwide, the prevalence of women smoking/ smokeless tobacco use is low, but the tobacco industry actively targets women, as an initiative to spend their market in using them to manufacture tobacco products like hand-rolled bidis, marketing, and also consumption as a symbol of women empowerment [15-18].

Socioeconomic differences and quit attempts in the present study did not reveal any significance but very few subjects from the low socioeconomic class tried to quit the smoking habit. E. Fernandez et al., T. Brown et al., and C.E. Sheffer et al. observed the socioeconomic differences in quit attempts, there could be a fiscal reason behind this quit attempt, in particular, tobacco taxation [19-20].

Our findings suggest that various cigarette promotional activities like free samples, cigarettes at the sale price, receiving coupons for purchase, gift, clothing, etc. were noticed by the participants in the last 30 days. The awareness of these specific types of cigarette promotional activities was high with a significant difference between the upper and lower class subjects. The study participants from the lower class more routinely noticed promotional activities by the tobacco companies; this could be attributed to the fact that these participants are the vulnerable targets for marketing, who are also less likely to support laws for smoke-free environments. The results of this study could be used to advocate the implementation of effective policies that show a higher impact among adults belonging to the lower socioeconomic class, such as raising prices of tobacco products and banning advertising, promotion, and sponsorship of tobacco products [21-22].

A potential limitation of our study is the possibility of the recall bias during the interview on tobacco use. A possibility of underestimation of the tobacco use by the respondents is expected as the subjects may hide the truth.

\section{Conclusions}

Our study results can conclude that the tobacco use pattern among various socioeconomic groups is insignificant, future attempts to reduce the tobacco use may not be specific for subgroups of the population. Meanwhile, efforts should be made to focus on people belonging to low socioeconomic strata, them being the easy targets for tobacco promotional activities by the tobacco industry. Still, considerable potential for development and implementation of effective strategies aimed at reducing tobacco use among different socioeconomic groups is the need of the hour. 


\section{Additional Information \\ Disclosures}

Human subjects: Consent was obtained by all participants in this study. YENEPOYA UNIVERSITY ETHICS COMMITTE issued approval YUEC09/09. Animal subjects: All authors have confirmed that this study did not involve animal subjects or tissue. Conflicts of interest: In compliance with the ICMJE uniform disclosure form, all authors declare the following: Payment/services info: All authors have declared that no financial support was received from any organization for the submitted work. Financial relationships: All authors have declared that they have no financial relationships at present or within the previous three years with any organizations that might have an interest in the submitted work. Other relationships: All authors have declared that there are no other relationships or activities that could appear to have influenced the submitted work.

\section{References}

1. World Health Organization: 2008-2013 Action Plan for the Global Strategy for the Prevention and Control of Noncommunicable Diseases. World Health Organization, Geneva, Switzerland; 2008.

2. Mathers C D, Loncar D: Projections of global mortality and burden of disease from 2002 to 2030. PLoS Med. 2006, 3:e442. 10.1371/journal.pmed.0030442

3. Cockerham GB, Cockerham WC: Health and Globalization. Polity Press, Cambridge; 2010.

4. Eriksen M, Mackay J, Ross H: The Tobacco Atlas, 4th Edition. American Cancer Society and New York, NY: World Lung Foundation, Atlanta GA; 2012.

5. World Health Organisation: Global Progress Report on Implementation of the WHO Framework Convention on Tobacco Control. World Health Organisation, Geneva, Switzerland; 2012.

6. Tata Institute of Social Sciences (TISS), Mumbai and Ministry of Health and Family Welfare Government of India 2016-17: Global Adult Tobacco Survey GATS 2 India . India;

7. Casetta B, Videla AJ, Bardach A, Morello P, Soto N: Association between cigarette smoking prevalence and income level: a systematic review and meta-analysis. Nicotine Tob Res. 2017, 19:1401-7. 10.1093/ntr/ntw266

8. Sreeramareddy CT, Harper S, Emstsen L: Educational and wealth inequalities in tobacco use among men and women in 54 low-income and middle-income countries. Tob Control. 2018, 27:26-34. 10.1136/tobaccocontrol-2016-053266

9. Marsh A, Mckay S: Poor Smokers. Policy Studies Institute, London; 1994.

10. Caroll ME, Anker JJ, Perry PL: Modelling risk factors for nicotine and other drug abuse in the preclinical laboratory. Drug Alcohol Depend. 2009, 104:70-8.

10.1016/j.drugalcdep.2008.11.011

11. Barreto SM, Giatti L, Casado L, de Moura L, Crepso C and Malta D: Contextual factors associated with smoking among Brazilian adolescents. J Epidemiol Community Health. 2012, 66:723-9. 10.1136/jech.2010.122549

12. Seidenberg AB, Caughey RW, Rees V W, Connolly GN: Storefront cigarette advertising differs by community demographic profile. Am J Health Promot. 2010, 24:26-31.

13. Lovato CY, Zeisser C, Campbell HS, et al.: Adolescent smoking effort of school and community characteristics. Am J Prev Med. 2010, 39:507-514. 10.1016/j.amepre.2010.08.019

14. Jarvis MJ: Why people smoke. BMJ. 2004, 328:277-9. 10.1136/bmj.328.7434.277

15. Toll BA, Ling PM: The Virginia slims identity crisis: an inside look at tobacco industry marketing to women. Tob Control. 2005, 14:172-180. 10.1136/tc.2004.008953

16. Mackay J, Amos A: Women and tobacco. Respirology. 2003, 8:122-30. 10.1046/j.14401843.2003.00464.x

17. Hitchman SC, Fong GT: Gender empowerment and female to male smoking prevalence ratios . Bull World Health Organ. 2011, 89:202. 10.2471/BLT.10.079905

18. Esteve Fernández, Anna Schiaffino, Carme Borrell, et al.: Social class, education, and smoking cessation: long-term follow-up of patients treated at a smoking cessation unit. Nicotine Tob Res. 2006, 8:29-36. 10.1080/14622200500264432 


\section{Cureus}

19. Brown T, Platt S, Amos A: Equity impact of population-level interventions and policies to reduce smoking in adults: a systematic review. Drug Alcohol Depend. 2014, 138:7-16.

10.1016/j.drugalcdep.2014.03.001

20. Sheffer CE, Stitzer M, Landes R, Brackman SL, Munn T, Moore P: Socioeconomic disparities in community-based treatment of tobacco dependence. Am J Public Health. 2012, 102:8-16. 10.2105/AJPH.2011.300519

21. WHO Report on the Global Tobacco Epidemic, 2008: The MPOWER Package . Geneva, Switzerland; 2008.

22. Lovato C, Linn G, Stead LF, Best A: Impact of tobacco advertising and promotion on increasing adolescent behaviours. Cochrane Database Syst Rev. 2003,

10.1002/14651858.CD003439 